\title{
KOMUNIKASI VERBAL DAN NONVERBAL PADA KOMUNITAS GAME CLASH OF CLANS
}

( Studi CMC pada Komunitas Indo ShadowsArmy )

\section{VERBAL AND NONVERBAL COMMUNICATION IN CLASH OF CLANS GAME COMMUNITY \\ (CMC Study of Indo ShadowsArmy Community)}

\author{
APRILIANTI PRATIWI ${ }^{1}$, NAILA HAKAMIHYA MAQAMAH ${ }^{2}$ \\ 'Universitas Pancasila, Jakarta ; ${ }^{2}$ Universitas Pancasila, Jl. Srengseng Sawah, Jakarta Selatan
}

Email : aprilyanti.mikom@gmail.com

\begin{abstract}
As a result of technological advances, many communities are now formed in the world of electronic communication. This study analyzes verbal and non verbal communication that occurs in the Clash of Clans game community, named Indo ShadowArmy. This study interviewed 6 members of Indo ShadowArmy. The methodology used in this study is qualitative with descriptive approach. Verbal and non-verbal communication in the Indo ShadowArmy community are: Indo ShadowArmy community members do not use words with abbreviated words and use of words, interpersonal conversations and unified narratives, calls on the regular Line application are light calls that are only used for member forces others, using a lot of terms in COC games, serious conversations that took place in the forum chatting took place during the war, the use of irony was never done, quite often using paralinguistic accounts that approach emoticons, calculating time for various topics that were very observing, have a fixed online schedule every day, "Social presence" members of the Indo ShadowArmy community on the chat and Line forums are evident, the message speed is faster and the response is fast too, because of feedback, rarely read before the message is sent to other members.
\end{abstract}

Key words : CMC, Clash of Clans, verbal communication, nonverbal communication, community

\begin{abstract}
ABSTRAK
Sebagai akibat dari kemajuan teknologi, kini banyak komunitas yang terbentuk dalam dunia komunikasi elektronik. Penelitian ini menganalisis komunikasi verbal dan non verbal yang terjadi pada komunitas game Clash of Clans, Indo ShadowArmy. Penelitian ini mewawancarai 6 anggota Indo ShadowArmy. Metodologi yang digunakan dalam penelitian ini adalah kualitatif dengan pendekatan deskriptif. Komunikasi verbal dan non verbal pada komunitas Indo ShadowArmy adalah: Anggota komunitas Indo ShadowArmy tidak menulis kalimat dengan bahasa yang baku dan menggunakan kata yang disingkat, percakapan antarpribadi dan narasi menyatu, percakapan pada aplikasi Line biasanya merupakan percakapan ringan yang hanya sekedar meminta troops atau menanyakan kabar anggota yang lainnya, banyak menggunakan istilahistilah dalam game $\mathrm{COC}$, percakapan serius yang terjadi di forum chatting terjadi
\end{abstract}


ketika sedang war, penggunaan ironi tidak pernah dilakukan, cukup sering menggunakan kial-kial paralinguistik yang berbentuk emoticon, perhitungan pemilihan waktu untuk membicarakan suatu topik sangat diperhatikan, memiliki jadwal online yang tetap setiap harinya, "Kehadiran sosial" anggota komunitas Indo ShadowArmy pada forum chatting dan Line nampak nyata, kecepatan penerimaan pesan menjadi cepat dan pemberian jawaban yang cepat pula, adanya umpan balik, jarang membaca ulang sebelum pesan dikirimkan pada anggota lainnya.

Kata Kunci: CMC, Clash of Clans, komunikasi verbal, komunikasi non verbal, komunitas

\section{PENDAHULUAN}

Salah satu tren hobi baru dikalangan muda dan dewasa di jaman teknologi canggih ini adalah game online. Pemain game atau yang biasa disebut gamer rela menghabiskan waktu berjam-jam di depan komputer, laptop atau gadgetnya untuk bermain game online, bahkan ada yang sampai mengeluarkan uang yang tidak sedikit. Andrew Rollings dan Ernest Adam (2006:770) menyebut game online bukan sekedar sebuah game permainan biasa, namun sebagai sebuah teknologi. Jika dibandingkan dengan pola tertentu dalam sebuah permainan, game merupakan sebuah media untuk menghubungkan pemain bersama.

Server dan client merupakan dua unsur utama dalam sebuah game online. Server melakukan administrasi permainan dan menjadi penghubung antar client, sedangkan client merupakan pengguna permainan yang memakai kemampuan server. Seiring perkembangan teknologi, kini game online telah bertransformasi menjadi bagian dari aktivitas sosial karena antarpemain dapat saling berinteraksi secara virtual bahkan sampai membentuk komunitas.

Salah satu komunitas yang terbentuk karena adanya aktivitas sosial di game online adalah komunitas Indo ShadowArmy. Komunitas Indo ShadowArmy ini merupakan komunitas yang terbentuk melalui hadirnya game online Clash of Clans (COC) pada smartphones platform los, di mana game ini memiliki fitur untuk berdiskusi yaitu chatting. Fitur chatting yang terdapat pada game ini digunakan sebagai sarana komunikasi antarpemain game atau anggota pada komunitas tersebut.

Pada game COC ini, fitur chatting dapat dilakukan secara global maupun clans. Komunikasi lewat fitur chatting dapat dilakukan jika seseorang sudah bergabung terlebih dahulu dalam sebuah clans. Setelah ikut bergabung dalam sebuah clans, pemain dapat bersosialisasi dan mendapatkan teman baru. Dalam sebuah clans, seorang pemain diwajibkan untuk dapat bekerjasama dengan sesama pemain agar tercipta kekompakan dan kesolidan untuk mengalahkan musuh. Dari intensitas chatting yang tinggi terjalinlah ikatan yang kuat antarpemain yang menumbuhkan rasa kebersamaan. Rasa kebersamaan bertambah ketika antaranggota bekerja sama dan bahu-membahu untuk menyusun strategi agar dapat mengalahkan lawan. 
Medium yang mewakili proses komunikasi yang terjadi antaranggota komunitas game COC ini adalah teks. Teks merupakan dasar dari komunikasi termediasi komputer. Teks menjadi bahasa internet yang diakui oleh semua peserta komunikasi termediasi internet.

Menarik untuk diketahui adalah bagaimana komunikasi verbal dan non verbal termediasi komputer yang dilakukan oleh anggota komunitas Indo ShadowArmy dalam menyusun strategi untuk mengalahkan lawan. Interaksi yang mereka lakukan adalah face to screen yang mengandalkan teks sebagai bahasa komunikasi mereka. Kita ketahui bahwa jika dibandingkan dengan komunikasi tatap muka, komunikasi teks hanya sedikit menampilkan gambar visual seperti ekspresi, emosi, dan intonasi.

\section{METODE PENELITIAN}

Penelitian ini mengunakan metode deskriptif dengan pendekatan kualitatif. Bogdan dan Taylor mendefinisikan metodologi kualitatif sebagai prosedur penelitian yang menghasilkan data deskriptif berupa kata-kata tertulis atau lisan dari orang-orang dan perilaku yang dapat diamati. Disebut deskriptif, karena dalam penelitian ini mempelajari masalah-masalah dalam masyarakat, serta tata cara yang berlaku dalam masyarakat serta situasi-situasi tertentu, termasuk tentang hubungan, kegiatan, sikap, pandangan, serta proses yang sedang berlangsung dan pengaruh dari suatu fenomena. Bogdan dan Taylor mengatakan metodologi kualitatif sebagai prosedur penelitian yang digunakan untuk menghasilkan data deskriptif, yang ditulis atau diucapkan orang dan perilakuperilaku yang dapat diamati.

Lokasi penelitian dilakukan di kota Depok, Provinsi Jawa Barat, Indonesia. Sumber data yang digunakan dalam penelitian ini dibedakan menjadi kata-kata dan tindakan, sumber data tertulis, foto, dan dokumentasi. Kata-kata dan tindakan merupakan data utama yang diperoleh melalui wawancara maupun observasi. Sumber informan penelitian ini adalah komunitas gameonline COC yang bernama Indo ShadowArmy dengan informan yang terdiri dari 5 orang anggota untuk mengetahui bagaimana komunikasi verbal dan nonverbal yang terjadi pada anggota dalam komunitas tersebut.

\section{A. Teknik Pengambilan Data}

Teknik pengumpulan data dalam penelitian ini adalah :

\section{Observasi}

Penelitian ini menggunakan teknik pengumpulan data dengan melakukan pencarian data secara observasi partisipan. Peneliti melakukan pengamatan sebagai peneliti partisipan dengan cara bergabung dalam komunitas game Clash of Clans selama dua bulan. Sebagai peneliti partisipan peneliti mengamati hal-hal yang relevan dan berhubungan dengan penelitian ini, yaitu bagaimana bahasa verbal dan non verbal yang terjadi pada proses komunikasi termediasi komputer anggota gameonline COC. 


\section{Wawancara}

Dalam penelitian dilakukan wawancara untuk memperoleh data yang lebih substansi. Menurut Mulyana (2008:180) wawancara adalah bentuk komunikasi antara dua orang dengan melibatkan seseorang yang ingin memperoleh informasi dari seseorang dengan mengajukan pertanyaan-pertanyaan, berdasarkan tujuan terntu. Peneliti melakukan kegiatan tanya jawab kepada narasumber, dan pertanyaan yang ditanyakan bersifat tak struktur karena pertanyaan yang diberikan pertanyaan terbuka yang belum ditentukan oleh peneliti dan juga dalam satu pertanyaan terkadang dapat dikembangkan lagi, selain itu wawancara dilakukan untuk memperkaya data primer dalam penelitian ini. Wawancara dilakukan terhadap lima anggota komunitas game COC.

\section{Studi Dokumentasi}

Dalam penelitian ini, peneliti menggunakan dokumentasi berupa captured atau screenshoot dari hasil percakapan yang diambil pada saat komunitas game Indo ShadowArmy diforum chatting aplikasi game COC dan aplikasi Line.

\section{HASIL DAN PEMBAHASAN}

Clash of Clans atau yang sering disebut COC merupakan game platform ios Android. Game yang memiliki alur cerita dan strategi ini dapat dimainkan secara individu maupun kelompok, yang mengharuskan pemain untuk membangun base atau sebuah desa untuk bertahan dari serangan base lain. Clash of Clans juga merupakan permainan yang memiliki beberapa keunikan, akun pada game ini dapat di perjual belikan kepada pemain lain dan harga yang ditawarkan cukup menjanjikan, karena base yang diperjual belikan adalah base yang memang sudah cukup besar. Semakin besar base tersebut maka akan semakin mahal harga yang akan di tawarkan. Game ini juga memiliki fitur yang di mainkan pada komputer yaitu terdapat sarana chatting, di mana pemain bisa saling berkomunikasi dan bertukar informasi.

Game yang dapat dimainkan secara individu dan kelompok ini memang memiliki keunikan tersendiri. Pemain game Clash of Clans dapat bergabung dengan clans lain jika bangunan clans sudah ada, manfaat bergabung dengan clans ialah untuk menambahkan loots. Dengan bergabung dengan clans lain, pemain akan mendapatkan lebih banyak informasi tentang cara membuat lebih kuat dan mengetahui bagaimana trik dan tips menyerang agar bisa mengahancurkan base lain.

\section{Komunitas Indo ShadowArmy}

Komunitas virtual merupakan komunitas yang lahir pada perkembangan teknologi. Salah satu komunitas yang hadir dalam perkembangan teknologi adalah komunitas yang ada pada game Clash of Clans, seperti salah satu contoh yaitu pada komunitas Indo ShadowArmy. Komunitas Indo ShadowArmy ini merupakan komunitas yang terbentuk melalui hadirnya game online Clash of Clans pada smartphones platform los, di mana pada game ini memiliki fitur untuk berdiskusi yaitu chatting. Fitur chatting yang terdapat pada game ini sebagai 
sarana komunikasi antar anggota member pada komunitas tersebut. Untuk bergabung dalam suatu komunitas tentunya ada syarat dan peraturan untuk menjadi anggota. Dalam komunitas Indo ShadowArmy, syarat untuk menjadi anggota yaitu anggota diharuskan sudah mencapai level TownHall delapan, mempunyai defense yang kuat, dan anggota juga harus loyal kepada anggota member yang lain.

Pada awalnya komunitas Indo ShadowArmy terbentuk dari perpecahan dua komunitas sebelumnya yaitu Depok Soldier dan All Indonesia, komunitas yang terbentuk dari delapan orang ini terbentuk pada tanggal 17 Mei 2014, di mana delapan orang ini mendirikan suatu komunitas baru sebab orang-orang yang merasa terbuang dan sakit hati ini merasa tidak nyaman dari komunitas sebelumnya. Pada komunitas sebelumnya anggota merasa tidak nyaman dari komunitas tersebut karena sering terjadi gesekan-gesekan konflik antara leader dan anggota, salah satu mantan anggota mengatakan bahwa dalam komunitas sebelumnya leader terlalu otoriter dan juga suka terbawa emosi, dimana sesuatu hal kecil dapat menjadi konflik sehingga anggota merasakan tidak leluasa dan tidak nyaman dalam memainkan game.

Komunitas Indo ShadowArmy dahulu memiliki jumlah anggota mencapai 50 orang yang kini jumlah anggotanya hanya 30 orang. Berkurangnya anggota dikarenakan, setiap war terjadi komunitas ini sering mengalami kekalahan. Salah satu faktor penyebabnya adalah banyak anggota yang sering tidak melakukan war, sehingga leader mengeluarkan anggota yang tidak aktif bermain, komunitas ini membatasi jumlah anggota hanya 30 anggota saja dan sampai sekarang komunitas ini berjalan dengan baik walaupun terkadang ada konflik, namun konflik yang terjadi hanya sementara. Dalam komunitas ini anggota lebih banyak didominasi dari wilayah kota Depok tetapi ada beberapa anggota yang tinggal di wilayah Nusa Tenggara Barat, dan Tanggerang.

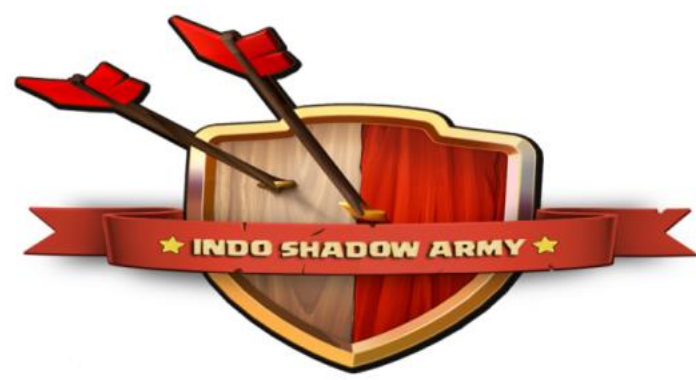

Gambar 1 Lambang Komunitas Indo ShadowArmy

Tugas dan jabatan yang terdapat dalam komunitas Indo ShadowArmy ini :

a. Leader

Pemimpin clans yang bertanggung jawab atas semua clans dan isinya serta dapat membuat sebagian besar keputusan. Tugas seorang leader yaitu mengundang pemain untuk bergabung dengan clans tersebut, menerima dan menolak permintaan untuk masuk dan bergabung dengan clans, dll. 
b. Co-leader

Tugas dari Co-Leader yaitu mengundang atau meng-invite pemain untuk bergabung di clans, menerima atau menolak pemain ke clans, mempromosikan dan menurunkan Elder, mengeluarkan anggota member clans dan Elder, dan memulai Clans War.

c. Elder

Tugas dari Elder ialah mengundang atau meng-invite pemain untuk bergabung di clans, menerima pemain untuk clans, dan mengeluarkan anggota clans.

d. Member

Jabatan yang secara otomatis didapatkan bila pemain telah bergabung atau kembali bergabung di clans.

Tabel 1 Unit Analisis Komunikasi verbal dan nonverbal dalam CMC

\begin{tabular}{|c|c|c|}
\hline No. & Jenis & Strategi dalam CMC \\
\hline 1. & Komunikasi verbal & $\begin{array}{c}\text { Norma-norma bahasa, Panduan skema } \\
\text { antarpribadi dan narasi, menggunakan } \\
\text { kalimat singkat dan padat, } \\
\text { memanfaatkan kosa kata, bahasa } \\
\text { partisipasi aktif, menggunakan ironi } \\
\text { secara tepat. }\end{array}$ \\
\hline 2. & Komunikasi nonverbal & $\begin{array}{c}\text { Kial-kial paralinguistik, Chronemics, } \\
\text { Frekuensi Komunikasi, Pesan yang } \\
\text { panjang, Cepat dalam memberi } \\
\text { jawaban, Umpan balik, Pesan yang } \\
\end{array}$ \\
& & akurat \\
\hline
\end{tabular}

Sumber: Iriantara $(2014,6.15-6.19)$

Game COC adalah satu dari sekian banyak gameonline yang cukup banyak peminatnya di Indonesia. Selain memiliki fitur-fitur yang menarik, gameonline ini juga sangat efisien karena game ini dapat diakses melalui smartphone sehingga dapat dimainkan kapan saja dan dimana saja. Salah satu fitur yang terdapat dalam game $\mathrm{COC}$ ini adalah fitur chatting.

\section{Computed mediated communication (CMC) pada Komunitas Indo ShadowArmy}

Di era globalisasi ini, komunikasi tidak hanya terjadi pada tatap muka (face to face) atau melalui media konvensional (surat, telepon, dll) tetapi juga melalui media baru. Akibat perkembangan media baru lahirlah Computed mediated communication (CMC) atau komunikasi yang termediasi komputer. Komunikasi ini terjadi pada anggota komunitas game COC yang bertemu dan berinterkasi dengan sesama anggota di arena virtual.

Bagi para anggota komunitas Indo ShadowArmy, game COC bukan hanya sekedar untuk mengisi waktu senggang saja, namun game ini sudah menjadi bagian dari aktifitas sehari-hari mereka. Dalam memainkan game ini para anggota dapat menghabiskan waktu delapan sampai sembilan jam dalam sehari 
bahkan sampai 12 jam sehari. Hal ini dikarenakan para anggota harus melindungi clans mereka dari serangan musuh.

Agar clans mereka tetap bertahan dan tidak diserang musuh, para anggota game COC harus mengatur strategi. Strategi dilakukan pada fitur chatting yang tersedia pada game ini. Menurut leader, co-leader dan elder jam-jam untuk chatting biasanya dilakukan pada saat malam hari karena pada siang hari banyak anggota komunitas Indo ShadowArmy yang bekerja. Namun aktivitas chatting pada siang hari tidak menutup kemungkinan untuk dilakukan. Biasanya chatting yang dilakukan pada siang hari hanya sebatas untuk meminta sebuah troops saja.

Komunikasi yang terjadi pada anggota Indo ShadowArmy tidak hanya terjadi melalui media chatting yang ada pada fitur game COC saja. Anggota komunitas ini menggunakan media lain untuk berkomunikasi dan memberi informasi tentang game, yaitu menggunakan aplikasi Line. Aplikasi Line digunakan ketika para anggota sedang tidak online di game COC. Leader membuat grup pada aplikasi Line agar mudah dalam penyebaran informasi seputar game ini. Seperti yang dijelaskan oleh Akbar berikut;

"Biasanya sih kalo member lagi ga online, gua ngasih taunya lewat grup Line, ya jadi komunitas clans gua punya group line, biar lebih gampang kalo ada info-info gitu." (31/12/2014)

\section{Komunikasi Verbal Komunitas Indo ShadowArmy}

1. Norma-norma bahasa dan penggunaaan kalimat singkat dan padat

Ketika ditanya mengenai penggunaan bahasa yang digunakan komunitas Indo ShadowArmy pada forum chatting dan aplikasi Line semua informan sepakat bahwa mereka menggunakan bahasa yang tidak baku. Mereka mengakui bahwa mereka pun sering menyingkat kata pada saat berkomunikasi di forum chatting dan Line. Berikut pengakuan Akbar Hariyanto Leader sekaligus pengurus blog komunitas Indo ShadowArmy: "Kalo chatting dan nge-Line kita pake bahasa sehari-hari aja. Biar cepet juga. Kalo ngga disingkat kan lama. Lagian kan ini forumnya nge-game bukan di kelas kalo gua lagi presentasi, hehehe... Gapapa anak-anak lain bahasanya gimana asalkan masih sopan." (30/12/2014)

\section{Paduan skema antarpribadi dan narasi}

Ditanya mengenai topik apa saja yang dibahas pada percakapan di forum game dan aplikasi Line, Akbar menjelaskan bahwa percakapan pada aplikasi Line biasanya merupakan percakapan ringan yang hanya sekedar meminta troops atau menanyakan kabar anggota yang lainnya. Ditambahkan pula oleh Akbar bahwa percakapan pun akan lanjut kepercakapan yang tidak ada hubungannya dengan game COC, seperti dijelaskan oleh Akbar berikut:

"Hmm ya biasanya awalnya cuma say hello aja. Nanya kabar aja. Trus lama-lama jadi ngobrolin kerjaan atau kuliahan gitu. Seru juga sih jadi akrab kita." (31/12/2014) 


\section{Memanfaatkan kosa kata}

Ketika ditanya mengenai seperti apa kosa kata yang biasa digunakan pada saat chatting di forum dan aplikasi Line, semua informan mengakui banyak menggunakan istilah-istilah dalam game COC. Mereka menyatakan bahwa penggunaan istilah-istilah ini memang wajar terjadi karena konteks pembicaraan memang seputar game COC. Berikut kutipan wawancara yang dilakukan dengan Syifa:

"Kita kalo ngobrol di forum chat pasti ada istilah COC gitu. Misalnya troops, tier troops, dragon, king barbarian, battle day, clans war, banyak deh." (31/12/2014)

4. Bahasa partisipasi aktif dan penggunaan ironi secara tepat

Ditanya mengenai bagaimana kalimat yang digunakan untuk mengundang lawan bicara agar terlibat dalam pokok pembicaraan bersama, beberapa informan mengakui hal ini dapat terjadi ketika sedang war. Sindir-menyindir pun tidak pernah terjadi karena diakui Rajib bahwa selama ini tidak pernah terjadi konflik antaranggota komunitas. Berikut kutipan wawancara dengan Rajib:

"Alhamdulillah ngga pernah ada konflik yah kita di sini. Paling banter serius ngomongin strategi perang aja. Kesel-kesel mah ada tapi kesel sama lawan pas lagi war. Tapi lucu juga, malah yang lain jadi ketawa kl ada yang kesel gitu." (30/12/2014)

\section{Komunikasi Non Verbal Komunitas Indo ShadowArmy}

1. Kial-kial paralinguistik

Ketika ditanya emoticon atau gambar seperti apa yang digunakan dalam percakapan di forum chatting dan aplikasi Line, Nden menjelaskan bahwa emoticon yang mereka gunakan adalah emoticon yang tersedia diaplikasi Line, yang biasa disebut sticker. Salah satu sticker yang digunakan di forum chat aplikasi Line komunitas Indo ShadowArmy adalah sticker dengan ikon pembawa acara 'The Comment' yaitu Dimas Danang dan Imam Darto. Seperti dijelaskan oleh Nden dalam potongan wawancara berikut:

"Kalo di Line kan banyak stiker lucu-lucu. Biasanya anak-anak lain juga pada pake stiker kok. Jadi kalo ngobrol di Line pake stiker biar rame. Untuk bilang 'ok' kita pake aja stiker yang ada 'oke'-nya. ... Macemmacem stikernya, ada yang pake stiker The Comment juga tuh." $(30 / 12 / 2014)$

Berikut potongan chatting pada aplikasi Line grup Komunitas Indo ShadowArmy: 


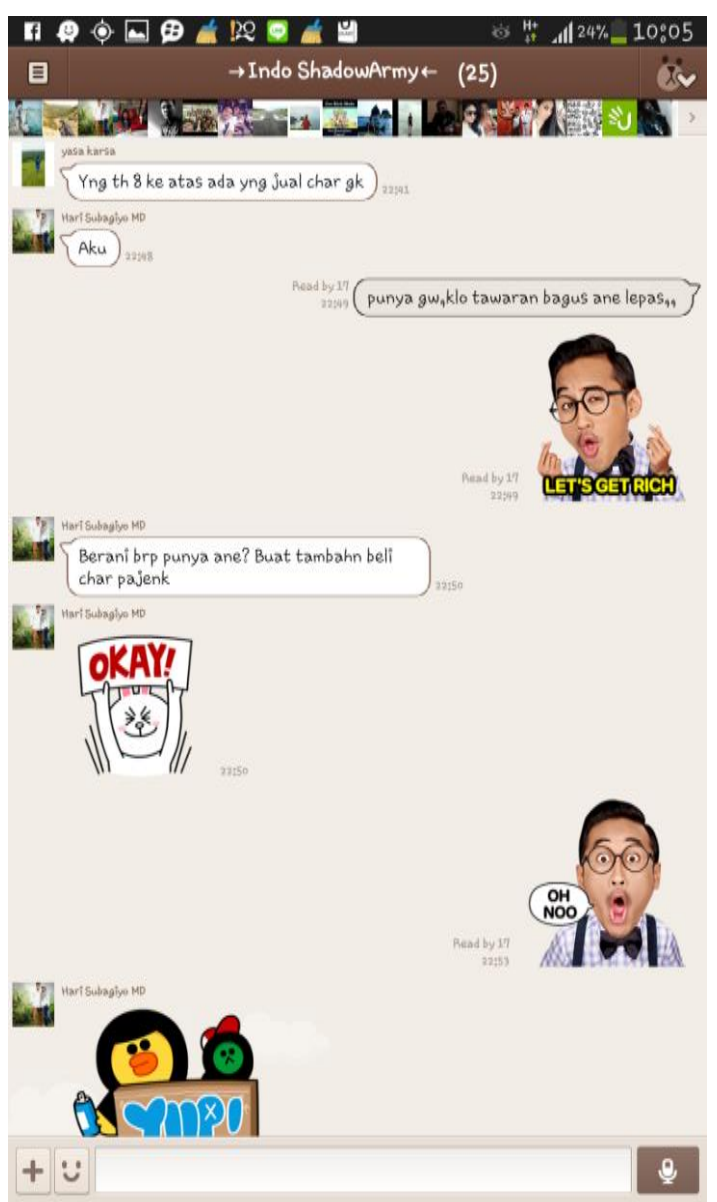

Gambar 2 Sticker Dimas Danang pada forum chatting aplikasi Line grup Indo ShadowArmy

\section{Kronemik dan Frekuensi Komunikasi}

Saat ditanya apakah saat hendak melakukan chatting perlu untuk mempertimbangkan waktu, Akbar menjelaskan itu sangat perlu. Mereka biasa chatting pada malam hari dimana semua anggota sedang bersantai di rumah.

"Kita punya jadwal online tetap setiap hari. Biasanya kita chatting-nya malam, kan udah pada nyantai tuh. Tapi siang-siang juga kadang ada yang chat cm minta troops doang." (31/12/2014)

\section{Pesan yang panjang}

Ketika ditanya mengenai pesan yang diketik pada saat chatting panjang atau pendek, informan mengakui terkadang mereka mnegtik pesan yang panjang. Berikut pernyataan Syifa:

"Pas waktu war, biasanya temen-temen pada serius tuh ngobrolnya. Biasa tentang strategi perang gimana, minta tolong juga." (30/12/2014)

4. Cepat memberi jawaban

Ketika ditanya apakah saat sedang chatting berlangsung informan segera memberikan jawaban, tanggapan atau respon Rajib, Nden dan 
Zaki sepakat menjawab ya. Namun mereka mengaku jika sedang jam kantor maka jawaban akan diberikan setelah selesai bekerja.

Berikut kutipan wawancara dengan Zaki:

"Kalo gua sih kalo ada Line masuk pas gua lagi kerja mah gua ngga cek. Ntar kalo gua udah beres kerja baru gua buka Line." (30/12/2014)

\section{Umpan balik}

Ditanya mengenai bagaimana kalimat yang digunakan untuk umpan balik, informan menjelaskan bahwa sebagian anggota ada yang memberikan umpan balik ketika chatting, namun ada juga yang cukup memantau saja. Hal ini dituturkan oleh Zakki dari hasil wawancara pada 31 Desember 2014:

"Ya kalo chatting si kalo anggota yang udah kenal mah biasa aja, ya sering nongol lah dalam chatting, trus jawab-jawaban gitu kalo ada yang ngajak chat. kalo yang belom kenal sih biasanya cuma mantau aja, lebih banyak diem, ya paling sama minta troops kalo lagi war"

\section{Pesan yang akurat}

Diakui oleh beberapa informan bahwa dalam mengetik pesan di forum chatting, jarang dari mereka membaca ulang sebelum pesan dikirimkan pada anggota komunitas lainnya. Hal ini sesuai dengan pernyataan Nden berikut:

"Gua kalo ngetik jarang liat lagi ketikan gua bener apa ngga tulisannya. Yang penting cepet kekirim aja pesen gua tadi." (31/12/2014)

\section{Diskusi}

Dibutuhkan dua komponen dalam proses CMC atau komunikasi termediasi komputer yang terjadi pada komunitas Indo ShadowArmy, yaitu komputer dan jaringan internet. Sebenarnya kedua hal ini belumlah cukup karena dalam komputer harus terdapat aplikasi yang memungkinkan anggotanya untuk dapat berkomunikasi. Aplikasi yang digunakan dalam proses CMC adalah apliklasi game COC dan aplikasi Line.

Jika seseorang sudah mempunyai loyalitas terhadap suatu komunitas maka kegiatannya dalam komunitas tersebut bukan hanya sekedar untuk mengisi waktu luang saja, namun telah menjadi bagian dari aktivitasnya seharihari. Inilah yang terjadi pada anggota komunitas Indo ShadowArmy. untuk memainkan game COC mereka rela menghabiskan waktu berjam-jam demi melindungi clans mereka dari serangan musuh.

Strategi dalam bertahan dan mengalahkan lawan diatur bersama dalam forum chatting yang tersedia pada aplikasi game ini. Biasanya waktu yang dipilih untuk membahas tak tik perang di forum chatting adalah saat malam hari. Pertimbangan pemilihan waktu malam hari dikarenakan tidak ingin mengganggu aktivitas anggota komunitas di pagi dan siang hari.

\section{Komunikasi Verbal Komunitas Indo ShadowArmy}


Dalam praktek CMC, anggota komunitas Indo ShadowArmy tidak menulis kalimat dengan bahasa yang baku. Dalam merangkai kalimatpun mereka menggunakan kata yang disingkat. Mereka tidak memikirkan panduan normanorma berbahasa. Hal ini dilakukan karena mereka menganggap bahwa forum chatting dan Line merupakan ruang yang tidak resmi dan bebas menggunakan bahasa apapun asalkan masih dalam batas wajar dan sopan.

Pada percakapan yang bersifat antarpribadi dan narasi menyatu dalam percakapan komunitas Indo ShadowArmy pada applikasi Line. Percakapan pada aplikasi Line biasanya merupakan percakapan ringan yang hanya sekedar meminta troops atau menanyakan kabar anggota yang lainnya. Namun percakapan tidak terputus hanya sampai disitu saja. Biasanya anggota lain akan lanjut kepercakapan narasi dengan menanyakan urusan pekerjaan atau perkuliahan dan urusan lainnya. Bahkan dengan percakapan narasi tersebut dapat mengeratkan hubungan antaranggota dan menciptakan kerjasama di dunia nyata.

Dalam percakapan di forum chatting anggota Indo ShadowArmy banyak menggunakan istilah-istilah dalam game COC. Penggunaan istilah ini tentu saja atas kesepakatan bersama dan dapat dipahami oleh semua anggota komunitas Indo ShadowArmy.

Percakapan serius yang terjadi di forum chatting terjadi ketika sedang war. Namun percakapan serius ini hanya seputar bagaimana mengatasi serangan lawan, strategi perang selanjutnya dan meminta bantuan anggota lain. Sering juga ada ungkapan-ungkapan kekesalan yang terlontar diforum chatting. Akan tetapi ungkapan kekesalan tersebut bukan ditujukan untuk anggota komunitas yang lain melainkan hanya merupakan ungkapan kekesalan terhadap pihak lawan. Jadi pada intinya selama ini belum pernah terjadi konflik antaranggota komunitas Indo ShadowArmy.

\section{Komunikasi Nonverbal Komunitas Indo ShadowArmy}

Dalam percakapan yang terjadi di forum chatting game COC dan aplikasi Line, anggota Indo ShadowArmy cukup sering menggunakan kial-kial paralinguistik yang berbentuk emoticon maupun gambar untuk mengungkapkan emosinya. Terdapat beberapa bentuk emoticon yang digunakan oleh informan yang mewakili perasaan mereka dalam aplikasi Line. Simbol-simbol tersebut berupa stiker-stiker yang dapat diunduh pada aplikasi Line. Stiker-stiker yang digunakan pada aplikasi Line diantaranya adalah stiker dengan icon pembawa acara The Comment yaitu Dimas Danang dan Imam Darto. Stiker digunakan untuk menggantikan kata "oke", mengekspresikan keterkejutan, terharu, dan lainlain.

Perhitungan pemilihan waktu untuk membicarakan suatu topik sangat diperhatikan oleh anggota komunitas Indo ShadowArmy. Mereka pun memiliki jadwal online yang tetap setiap harinya. Jam-jam untuk chatting biasanya dilakukan pada saat malam hari. Hal ini dikarenakan sebagian anggota beraktivitas pada siang hari. Namun chatting pada siang hari tidak menutup 
kemungkinan masih dapat dilakukan. Biasanya chatting yang dilakukan pada siang hari hanya untuk sekedar meminta sebuah troops saja.

"Kehadiran sosial" anggota komunitas Indo ShadowArmy pada forum chatting dan Line dapat dikatakan nampak nyata. Hal ini dapat dilihat dari pesan yang diketik pada forum chatting dan Line cukup panjang. Sebagian besar anggota memberikan pesan yang panjang. Terlebih chatting dilakukan pada saat war, para anggota akan saling memberikan pesan serius terkait strategi perang agar dapat menjatuhkan lawan.

Semua informan memiliki handphone berjenis smartphone, sehingga kecepatan penerimaan pesan menjadi cepat dan berimbas pada pemberian jawaban yang cepat pula. Namun terkadang pemberian jawaban mereka tunda ketika mereka sedang melakukan aktivitas yang sangat penting.

Dalam proses CMC atau komunikasi yang termediasi komputer yang terjadi antar anggota komunitas Indo ShadowArmy ini, terdapat beberapa gaya komunikasi yang berbeda. Perbedaan gaya berkomunikasi terjadi pada anggota yang sudah saling kenal secara personal dan anggota yang belum saling kenal secara personal. Anggota yang sudah saling mengenal satu sama lain akan berkomunikasi seperti teman yang sudah akrab. Dalam percakapan mereka terdapat canda dan saling ejek satu sama lain. Umpan balik yang diberikan mampu mencairkan suasana sehingga terjadi tek-tok yang cukup signifikan. Umpan balik yang terjadi mampu mengembangkan hubungan antarpribadi yang baik dan mengakrabkan suasana forum chatting. Salah satu indikator dari keakraban yang terjadi pada anggota komunitas ini adalah mereka sudah pernah bertemu secara offline.

Berbeda halnya dengan gaya komunikasi yang terjadi pada anggota yang belum atau tidak saling kenal. Biasanya ini terjadi pada anggota yang baru bergabung dalam komunitas ini. Mereka berkomunikasi seadanya dan cenderung lebih pasif. Bahkan ada anggota yang sama sekali tidak berkomunikasi dalam ruang chatting. Mereka hanya mengamati pesan-pesan yang terdapat di forum chatting tersebut. Ada kecanggungan yang dirasakan oleh anggota baru komunitas ini. Mereka terkesan malu dan canggung untuk ikut dalam obrolan di forum chatting.

Pada saat mengetik pesan di forum chatting, anggota komunitas Indo ShadowArmy jarang membaca ulang sebelum pesan dikirimkan pada anggota lainnya. Hal ini mengakibatkan seringkali terjadi kesalahan ketik. Namun hal ini dimaklumi oleh sesama anggota lainnya karena kesalahan ketik yang terjadi dianggap diakibatkan oleh mengetik pesan yang terburu-buru agar pesan cepat terkirim dan cepat direspon oleh anggota lainnya.

\section{SIMPULAN}

Penulis telah melaksanakan penelitian mengenai komunikasi verbal dan non verbal pada komunitas Indo ShadowArmy serta menemukan kesimpulan, sebagai berikut: 
a. Anggota komunitas Indo ShadowArmy tidak menulis kalimat dengan bahasa yang baku. Dalam merangkai kalimat pun mereka menggunakan kata yang disingkat.

b. Pada percakapan yang bersifat antarpribadi dan narasi menyatu dalam percakapan komunitas Indo ShadowArmy pada applikasi Line. Percakapan pada aplikasi Line biasanya merupakan percakapan ringan yang hanya sekedar meminta troops atau menanyakan kabar anggota yang lainnya.

c. Dalam percakapan di forum chatting anggota Indo ShadowArmy banyak menggunakan istilah-istilah dalam game COC.

d. Percakapan serius yang terjadi di forum chatting terjadi ketika sedang war. Namun percakapan serius ini hanya seputar bagaimana mengatasi serangan lawan, strategi perang selanjutnya dan meminta bantuan anggota lain.

e. Penggunaan ironi tidak pernah dilakukan karena selama ini belum pernah terjadi konflik antaranggota komunitas Indo ShadowArmy

f. Anggota Indo ShadowArmy cukup sering menggunakan kial-kial paralinguistik yang berbentuk emoticon maupun gambar untuk mengungkapkan emosinya

g. Perhitungan pemilihan waktu untuk membicarakan suatu topik sangat diperhatikan oleh anggota komunitas Indo ShadowArmy. Mereka memiliki jadwal online yang tetap setiap harinya.

h. "Kehadiran sosial" anggota komunitas Indo ShadowArmy pada forum chatting dan Line dapat dikatakan nampak nyata. Hal ini dapat dilihat dari pesan yang diketik pada forum chatting dan Line cukup panjang.

i. Semua informan memiliki handphone berjenis smartphone, sehingga kecepatan penerimaan pesan menjadi cepat dan berimbas pada pemberian jawaban yang cepat pula.

j. Anggota yang sudah saling mengenal satu sama lain akan berkomunikasi seperti teman yang sudah akrab dan memberikan umpan balik ketika di dalam forum chatting.

k. Pada saat mengetik pesan di forum chatting, anggota komunitas Indo ShadowArmy jarang membaca ulang sebelum pesan dikirimkan pada anggota lainnya.

\section{SARAN}

\section{Saran untuk penelitian selanjutnya}

Bagi peneliti yang akan melakukan penelitian selanjutnya, diharapkan dapat mengumpulkan data lebih detil lagi terutama aktivitas komunikasi para informan di forum chatting.

\section{Saran untuk anggota komunitas Indo ShadowArmy}

Agar setiap anggota komunitas menggunakan bahasa yang baku dan tidak menyingkat kata-kata dalam kalimat agar informasi yang disampaikan jelas. 


\section{DAFTAR PUSTAKA}

Iriantara, Y. 2004. Community relations konsep dan aplikasinya. Bandung: PT Remaja Rosdakarya Offset.

-

J. Moleong, L. 2004. Metodologi Penelitian Kualitatif. Bandung : Rosda Karya

Kriyantono, R. 2010. Teknis Praktis Riset Komunikasi. Jakarta: Kencana

Mulyana, D. 2003. IImu Komunikasi Suatu Pengantar. Bandung : PT. Remaja Rosdakarya

\& Rakhmat, Jalaluddin. 2005. Komunikasi Antar Budaya. Bandung: Pt.Remaja Rosdakarya.

----.-. 2008. Metodologi Penelitian Komunikasi. Bandung. Remaja Posda Karya.

Nasrullah, R. 2012. Komunikasi Antarbudaya di Era Budaya Siber. Jakarta:Kencana, Prenada Media Group.

Rollings, A. dan Ernest Adams. 2006. Fundamentals of Game Design (Game Design and Development Series). Prentice Hall. p. 600. ISBN 978-0-13168747-9.

Sugiyono. 2011. Metode Penelitian Kuantitatif, Kualitatif, dan R\&D. Bandung: Alfabeta 